\title{
Modeling and mapping of climatic classification of Pakistan by using remote sensing climate compound index (2000 to 2018)
}

\author{
Kanwal Javid ${ }^{1}$ (D) - M. Ameer Nawaz Akram ${ }^{1}$ Maria Mumtaz ${ }^{1} \cdot$ Rumana Siddiqui $^{2}$
}

Received: 14 December 2018 / Accepted: 31 July 2019 / Published online: 17 August 2019

(c) The Author(s) 2019

\begin{abstract}
The entire world is collectively facing the problem of climate change. The deterioration of the earth's climate change is being noticed and felt most apparently in Southeast Asia and predominantly in Pakistan. Pakistan is a victim of climate change, due to which Pakistan faces several geographical, political, economic and even social problems. The harmful impacts of climate change in the form of smog and abnormal heat waves have claimed the life of many Pakistanis. Climate change has brought disastrous impact on the agrarian economy of Pakistan, which has plunged the country into awful straits. Climatic change is a slow and continuous process. It is needed that climatic changes in an area should be traced out in time to face upcoming climatic challenges. Present research work has traced out such changes and introduced a new climatic classification scheme for the climate of Pakistan, by using remote sensing (RS) and a new climatic compound index that is RSCCI gives a calculated value, which is used to describe the state and the changes in the climatic system of an area. RSCCI is the combination of different indices. On the basis of RSCCI, a climatic index, spatiotemporal investigation is conducted to measure aridity, humidity and semi-aridity all over Pakistan. In order to find out the extent of these climatic conditions, three MODIS dataset images of $250 \mathrm{~m}$ resolution were acquired. RS applications are used effectively to assess the changing climatic trends for the period of eighteen years in Pakistan from 2000 to 2018. On the basis of the above-mentioned results, a new climatic classification has been introduced with five major classes, i.e., drought, aridity, humidity, wetlands and cold drought. The area of five classes has been calculated by using RS tools and RSCCI for the years of 2000 and 2018. New climatic classification of Pakistan divides Pakistan into five regions which is based on RSCCI . There is an increase in arid region of 1.84\% in Pakistan from RSCCI 2000 to RCSSI 2018. Similarly, there is also increase in an area of wetlands and humid regions of Pakistan, i.e., 1.9\% and 9.72\%, respectively, from RSCCI 2000 to RCSSI 2018. On the other hand, there is $0.78 \%$ reduction of area of cold drought region, $8.49 \%$ reduction in moderate drought and $4.19 \%$ reduction in an area of intense drought classes from RSCCI 2000 to RCSSI 2018, which is a positive change. The results show dramatic changes which advocate the need of a new climatic classification for Pakistan. This new climate classification of Pakistan is based on 18 years of data only. Dramatic climatic changes could be imagined and predicted within next 30 years in Pakistan.
\end{abstract}

Keywords RSCCI $\cdot$ Climatic index $\cdot$ Climate change $\cdot$ MODIS $\cdot$ Remote sensing

Kanwal Javid

Knwl.j92@gmail.com

M. Ameer Nawaz Akram

ameerhussain92@gmail.com

Maria Mumtaz

mariamumtazlc@gmail.com

Rumana Siddiqui

rumanasiddiqui5@gmail.com

1 Department of Geography, University of the Punjab, Lahore, Pakistan

2 Department of Geography, Queen Mary College, Lahore, Pakistan

\section{Abbreviations}

MODIS Moderate resolution imaging spectroradiometer

RS Remotes sensing

RSCCI Remote sensing climatic compound index

WMO World meteorological organization

PET Potential evapotranspiration

ETo Evapotranspiration

GISc Geographic information sciences

LST Land surface temperature

NDSI Normalized difference snow index

NDVI Normalized difference vegetation index

TNDVI Transformed normalized difference vegetation index 


$\begin{array}{ll}\text { MSI } & \text { Moisture stress index } \\ \text { SAVI } & \text { Soil-adjusted vegetation index } \\ \text { USGS } & \text { United states geological survey } \\ \text { AOI } & \text { Area of interest } \\ \text { SWIR } & \text { Short wave infrared } \\ \text { NIR } & \text { Near infrared } \\ \text { KPK } & \text { Khyber pakhtunkhwa } \\ \text { CCPI } & \text { Climate change performance index }\end{array}$

\section{Introduction}

Climate change has been one of the most talked about issue, particularly since the start of the twenty-first century. Climate is usually defined as an average weather in a narrow sense or more thoroughly, as the statistical description in terms of the mean and variability of relevant quantities over a time ranging from months to thousands or millions of years. The classical period for averaging these variables is 30 years, as defined by the World Meteorological Organization. The relevant quantities are most often surface variables such as temperature, precipitation and wind. Climate in a wider sense is the state that includes a statistical description of the climatic system (Odoh and Chilaka 2012).

According to World Meteorological Organization (WMO), over a long period of time, more than several years, climate is the statistical description in terms of the mean and variability of relevant quantities, and it is duration over years and decades, usually over 30 years. The dissimilar pattern of climate distinguishes from similar ones by using such classification of climate (Walterscheid 2011). Forming a classification system of climate is a very tough and a hard job. Many climatologists gave different climatic classification on the basis of their own experiences and criteria. "Climatic classification is merely a method of arranging various climatic parameters either singly or grouped into ranks or sets, so, to as both simplify the mass of data and to identify analogies" (Griffiths 1978). Qualitative, as well as quantitative, approaches are used not only in Pakistan but also all over the word to determine the climate classification. The climatic classification given on the basis of different approaches is different from each other. Permanide was the first Greek philosopher who divided the climate of the world based on solar concentration. Then the other well-known scientists (Koppen 1846-1940; Thornthwaite 1931, 1948; Blair 1942; Griffiths 1978) gave their own climatic classification of the world. On the other hand, excellent work on the climatic classification of Pakistan has been done by Kazi (1951), Shamshad (1986) and Khan et al. (2010)

Koppen classification was temperature based and developed by climate indices, despite zone variation among themselves. Globally, therefore, there was some lapse in it (Kopeen 1936). In 1948, Thornthwaite had introduced a climate classification based on rainfall and potential evapotranspiration (PET). This approach was adopted by various regions of the world for classification. The climate of Pakistan has been characterized by adopting Reddy-modified Thornthwaite approach using reference crop evapotranspiration (ETo) instead of potential evapotranspiration (PET) (Reddy et al. 1973). Thermal efficiency index (TEI) was also developed by Thornthwaite for climate classification (Thornthwaite 1948). There is indication of thermal periphery and the requirement of water in different climate types, because it is a growth index. This approach is also widely used around the world by different climatologists and scientists (Villmow 1962). The agro-climatic classification for Asia and Africa had been done by the United Nations Environment Program (White 1998). Pakistan has arid to semiarid climate with great variability in temperature (Chaudhary and Rasul 2004).

Remote sensing has been in used for spatial evaluation of an area, in the world of geographic information system. All the climatological and geographical aspects can be interpreted in a manageable way by using RS and GIS. The temporal estimation of land surface temperature (LST), normalized difference vegetation index (NDVI), soil-adjusted vegetation index (SAVI) and moisture stress index (MSI) is done from 2000 to 2017 which clearly shows that stress on soil moisture increased in Kalat region of Pakistan that ultimately leads to aridity (Batool and Javid 2018). Pakistan is basically a semiarid region, and it has been classified into five regions (hot, warm, mild, cool and cold), based on temperature. The southern half experiences high temperatures and decreases while heading toward northern half of Pakistan. The eastern part of Pakistan receives heavy rainfall in summers due to monsoon, while western parts receive heavy rain in winters due to western disturbances. The most suitable area for crop production lies between $33^{\circ} \mathrm{N}$ and $35^{\circ} \mathrm{N}$ due to rain fed conditions. The agricultural production above and below these latitudes is only possible if there are supplementary conditions available for irrigation (Chaudhary and Rasul 2004). This is an era of information and technology which makes accessibility of spatial data for scientists and researchers on a broad scale. Access to aerial and satellite imagery is very helpful for them to study the climatic condition of an area. They can even predict changing climatic trends of an area by using RS applications. So, the main objective of this research is the formation of new climatic classification of Pakistan by using the remote sensing techniques. A new climatic classification of Pakistan is proposed by introducing an innovative climatic compound index that is RCCI. Comparative approach is used to modulate the revised classification of climate for Pakistan. The entire process has been done by creating a mosaic which is also applied to mix all the components of MODIS data of 
selected study area. Arc GIS10.5 and ERDAS Imagine 2015 are used to conduct analysis and generate maps.

\section{Materials and methods}

RS applications are used effectively to assess the changing climatic trends of Pakistan from 2000 to 2018. A spatiotemporal investigation is conducted to measure aridity, humidity and semiaridity all over Pakistan. In order to find out the extent of these climatic conditions all over Pakistan, three MODIS dataset images of $250 \mathrm{~m}$ resolution were acquired for the years 2000 and 2018. These images were obtained from USGS, an earth observatory website. In this present research, a new climatic classification of Pakistan has been introduced by using RS climatic compound index (RSCCI).

The entire process has been done by creating a mosaic which is also applied to mix all the components of MODIS data of the selected study area. Sticking with the operation of layer stacking, sub-setting of the mosaic image was performed through the clipping process by using digitized boundaries of the area of interest (AOI).

\section{Study area}

Pakistan is in the northwestern part of great Indo-Pak subcontinent. It is a beautiful country starting from Himalayan Mountain in the north, with plains in the Punjab and Sindh, to long stretched coastal boundaries in south of Sindh and Baluchistan. Its geographical coordinates are $30.3753^{\circ} \mathrm{N}$ and $69.3451^{\circ} \mathrm{E}$. Pakistan is surrounded by countries of Iran, Afghanistan, China and India with a coast on the Arabian Sea. The total area of Pakistan is $803,936 \mathrm{~km}^{2}$. It is a land of varied landscapes ranging from perpetually snow capped peaks of Himalayan range like the Karakoram, K-2 elevation $28,265 \mathrm{ft}$. (8615 m) to lush green canal irrigated areas. Pakistan is in temperate zone; therefore, monsoon keeps the temperature cold, moderate and rainy in December, extremely hot and dry in April, hot and very humid in September and cool to dry in November. Due to the presence of monsoonal activity in Pakistan, the overall climate of Pakistan remains arid and semiarid (ICID 2005; Batool and Javid 2018). The study area map of Pakistan is shown in Fig. 1

\section{Remote sensing data analysis}

Reflection is very important for the satellite sensors to capture the images and features of the earth. Solar energy can be absorbed, transmitted or spread out with interaction processes. Land covers do not absorb and reflect the radiation equally. All land covers behave differently due to their characteristics. For example, vegetation reflects highly in the infrared zone and near-infrared zone of the electromagnetic spectrum. Furthermore, spectral signatures are used to differentiate the earth's surface substances. The chlorophyll content in leaves plays a very important role in absorption, transmission and reflection. Vegetation cover, arable land, soil, water bodies and physical structure of the earth should reflect differently from each other, vary from place to place and connected with the angle of the sun, an angle of the sensor and time of capturing the land surface by the satellite sensor. Water has less than $10 \%$ reflectance, and it is shown only in the visible range $(0.4-0.7 \mu \mathrm{m})$. On the other hand, water absorbs all energy in the long range than $0.75 \mu \mathrm{m}$. Vegetation highly absorbs the radiation and reflects the energy in the infrared and near-infrared range, and at $0.65 \mu \mathrm{m}$ vegetation highly reflects due to the presence of chlorophyll. Furthermore, $1.45-1.55 \mu \mathrm{m}$ and $1.90-1.95 \mu \mathrm{m}$ are high absorption ranges, due to the presence of water content in leaves. The soil has very less reflection curve with high reflection values as compared to vegetation and water because soil absorbs and reflects the high flux of energy. It goes to more high levels when bands increase. Its curve is formed due to the presence of water in the soil. During the integration of plant types and their leaves in infrared region, photosynthesis works properly and absorbs the radiation from 70 to 90\% (Siddiqui and Javid 2018; Campbell 1996).

\section{Data acquisition}

For the assessment of climatic conditions of any region, remote sensing technique became an essential tool in the last decades; four sets of remotely sensed data are applied to analyze the climatic condition of Pakistan (Table 1). In order to find out the climatic condition of Pakistan, three MODIS dataset images of the study area are acquired for 2000 and 2018. These images were obtained from the United States Geological Survey (USGS), an Earth Observatory website.

\section{Remote sensing climatic compound index (RSCCl)}

In Eq. 1, RCSSI is a new climatic compound index which is introduced for a new climatic classification study area, based on some parameters which include temperature, vegetation, evapotranspiration, snow, water and soil moisture of Pakistan because the climate is mainly affected by these factors naturally. LST is land surface temperature. LST is highly accelerated by the loss of vegetation, soil moisture content and increased temperature and is activated by anthropogenic activities (Kang et al. 2010). LST is one of the global challenges that is directly involved in urban developing activities and hinders sustainable development growth (Adam et al. 2015). In the above Eq. 1, digital numbers (values of DN) acquired from the United States Geological Survey (USGS) of the image were calculated and their average was taken out. Firstly, DN was converted to radiance by multiplying

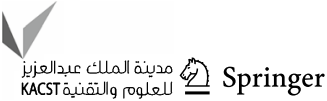




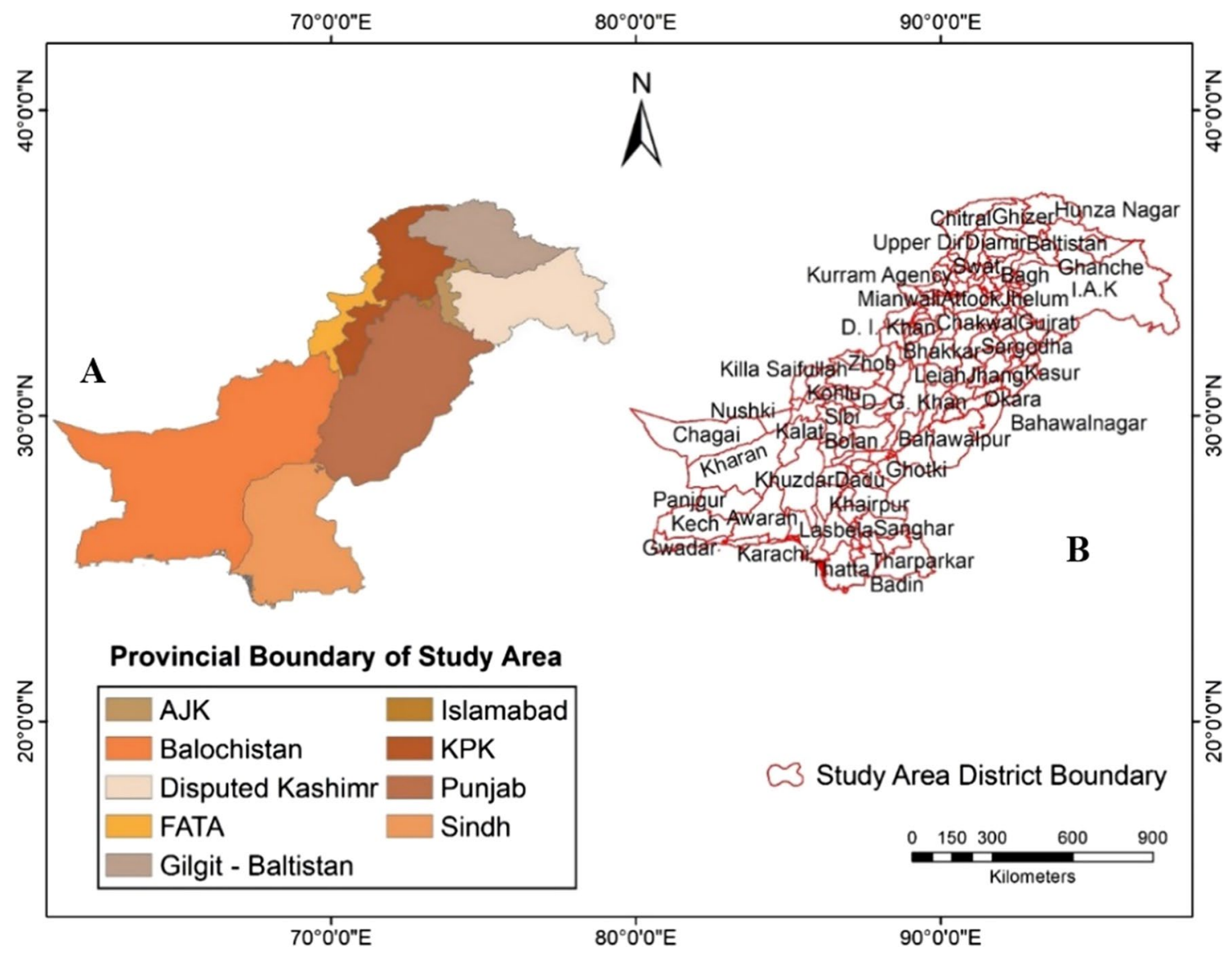

Fig. 1 Spatial location of Pakistan; A shows provincial boundaries of Pakistan, while B shows district boundaries of Pakistan. This figure shows the study area. Boundary of Pakistan in two prospects as A and B: A shows provincial boundary of Pakistan with different color sym-

Table 1 Characteristics of remotely sensed data used for desertification analysis

\begin{tabular}{lllll}
\hline Sr. No. & Year & Satellite & Sensor & $\begin{array}{l}\text { Spatial } \\
\text { resolution } \\
(\mathrm{m})\end{array}$ \\
\hline 1 & 2000 & MODIS & MOD13Q1, MOD11A2 & 250 \\
2 & 2018 & MODIS & MOD13Q1, MOD11A2 & 250 \\
\hline
\end{tabular}

with 0.02 . Secondly, for the conversion of radiance Kelvin values into degree Celsius are subtracted with 273.15 (Siddiqui and Javid 2018; Mazher et al. 2018; Batool and Javid 2018). In order to differentiate between cloud and snow pixels, the snow cover was extracted with band 2 - band 5/ band $2+$ band 5 ; band 2 represents Green band which shows more reflectance of snow and band 5 is NIR band in Eq. 1 (Kulkarni et al. 1992). It helps to monitor and evaluate the healthy vegetation and green cover areas. It is generally correlated with biophysical characteristics of vegetation, e.g., green biomass, leaf area index and chlorophyll moisture in bology and label and shows provinces as Punjab, Sindh, Balochistan, KPK, FATA, Gilgit Baltistan, Azad Jammu Kashmir (AJK), Disputed Kashmir and Islamabad. B shows districts boundary of provinces of Pakistan in red color

the leaves (Prince et al. 1995; Goward et al. 1985; Justice et al. 1985). Rouse et al. (1973) first used normalized difference vegetation index (NDVI) as a numerical indicator for vegetation monitoring. NDVI has the potential to relate climate changes with vegetation responses (Xu et al. 2011). Areas with least vegetation experience more land surface temperatures (Rahman et al. 2004a, b). NDVI has been widely used in semiarid and arid regions for vegetation production, soil moisture estimation, crop yield assessment and drought detection (Haroon et al. 2016: Allen et al. 2005; Rahman et al. 2004a, b; Peters et al. 2002; Moulin et al. 1998; Bausch 1995; Choudhury et al. 1994; Benedetti and Rossini 1993). According to Gamo et al. (2013), the distribution of NDVI is like the trends in the aridity index, which increases from dry land to wetland. NDVI is calculated using the $(\mathrm{NIR}-\mathrm{R}) /(\mathrm{NIR}+\mathrm{R})$. NIR is near-infrared band value and red band value is denoted with $\mathrm{R}$. According to Greenland (1994), TNDVI is an integrated function of photosynthesis, leaf area and evapotranspiration. It is a symbol of vegetation biomass, and it is a ratio between near-IR and red reflection. 
The total amount of biomass has indirect and direct relation with surface energy balance; the surface temperature is consistent with the interference of sunlight, canopy cover ratio and with evapotranspiration cooling effect (Yang et al. 2008; Sandham and Zietsman 1997; Friedl and Davis 1994). Moisture Stress Index (MSI) is a water ratio index that finds the water content in vegetation or leaf relative. Soil moisture plays a significant part in growing vegetation from the roots rather than precipitation (Soni et al. 2017). It is normally estimated from MODIS data that uses SWIR band instead of MIR because of band's sensitivity to moisture. The ratio between SWIR and MIR reduces scattering effect and dominates water variation in vegetation (Zhang et al. 2013). Area of vegetation land cover is very low without the influence of soil brightness (Lyon et al. 1998; Rondeaux et al. 1996; Senseman et al. 1996; Richardson and Everitt 1992; Huete 1988). According to Huete (1988), the soil-adjusted vegetation index is a key factor to find out the area of low or no vegetation and exposed soil surface. In arid areas, it is considered preferable to use a soil-adjusted vegetation index and modified soil-adjusted vegetation index (Qi et al. 1994), and for the reflectance of soils different amounts of illumination in the red and near-infrared wavelengths is considered (Huete et al. 2002). NIR is near infrared band value, RED is reflectance of the red band and $\mathrm{L}$ is soil brightness component. The value of $L$ varies with the amount of green vegetation cover in very high vegetation regions, $L=0$; in no green vegetation region, $L=1$. Generally, $L=0.5$ works well in most scenarios and is used as default value (Rondeaux et al. 1996; Huete 1988). change observed in 2018 map. The intensity of drought is decreasing and is converted into humid regions with intensify vegetation cover in northern or middle area of Baluchistan, in western or south east region of the Punjab and south region of KPK. The said areas were drought prone in 2000 map, and now there is a good change and they are converted into wetland with much vegetation cover in 2018 map. Similarly, yellow color in Figs. 2 and 3 shows the arid regions of Pakistan which mostly includes middle and southern parts of Pakistan in 2000. The aridity is mostly observed in the province of Punjab, Khyber Pakhtunkhwa and northern part of Baluchistan in 2018. This progressive increase in the area of aridity in 18 years is mainly due to abrupt change in climate, land surface temperature change and reduction in precipitation of Pakistan. Now, the direction of aridity is extended toward the northern cold wet regions of Pakistan in 2018. The shades of green in legend of Figs. 2 and 3 are classified as humid regions in climatic classification. These regions predict the major changes in Pakistan climatic distribution map from 2000 to 2018 . There is huge positive change again observed in 2018 map in case of humid regions, while major vegetation land cover is much less in the 2000 map. It is estimated that the humid or vegetation regions are increased in 2018 due to highest atmospheric and land surface temperature along with climatic change which cause faster melting of snow or glaciers in the northern region of Pakistan. By melting of snow, water level increased due to the lack of proper developed drainage system and having insufficient storage capacity. Soil moisture increases naturally in alluvial plain regions of Pakistan. Such

Remote Sensing Climatic Compound Index(RSCCI)

$$
=\left\{\frac{[\mathrm{DN} * 0.02-(273.15)]+\left[\frac{\text { Band 2-Band 5 }}{\text { Band 2+Band 5 }}\right]+\left[\frac{(\mathrm{NIR}-\mathrm{R})}{(\mathrm{NIR}+\mathrm{R})}\right]+\left[\sqrt{\left(\frac{(\mathrm{Infrared}-\mathrm{Red})}{(\text { Infrared }+ \text { Red })}\right)+0.5}\right]+\left[\frac{\mathrm{RSWIR} 6}{\mathrm{RNIR}}\right]+\left[\mathrm{NIR}-\left(\frac{\mathrm{RED}}{\mathrm{NIR}}+\mathrm{RED}+\mathrm{L}\right) *(1+\mathrm{L})\right]}{6}\right\}
$$

\section{Results and discussion}

Figures 2 and 3 show the new climatic classification of Pakistan by using remotely sensed images collaborated with compound indices mentioned in Eq. 1. As a result, new compound climatic index (RSCCI) is made. By using this purely new technique index, a new climatic classification is made, from 2000 to 2018, for Pakistan. In this index, Pakistan is divided into five climatic regions, shown in Figs. 2 and 3 through different colors such as dark brown and orange which predict the drought regions of Pakistan from 2000 to 2018. The whole part of the Sindh province, southern part of the Punjab and a major part of Baluchistan are shown as drought regions in the image of 2000 , but there is an obvious unmanageable water can also be a cause of extensive flooding every year. It is shown in Figs. 1 and 2 that the southern and central Punjab, northern part of Baluchistan and a small part of Sindh were in drought region in 2000 but now are converted into humid or vegetation land cover regions of Pakistan. Dark blue and cyan color in legend show the wetland regions, which are mostly located near the snow cover or glacier areas. There has also been more melting snow or glacier from 2000 to 2018 , and there is significant increase in the area of wetland of Pakistan from 2000 to 2018. The regions which are shown with purple and white color in the legend of Figs. 2 and 3 are classified as cold drought regions. This area is permanently under snow cover and shows no vegetation cover; therefore, they are classified 


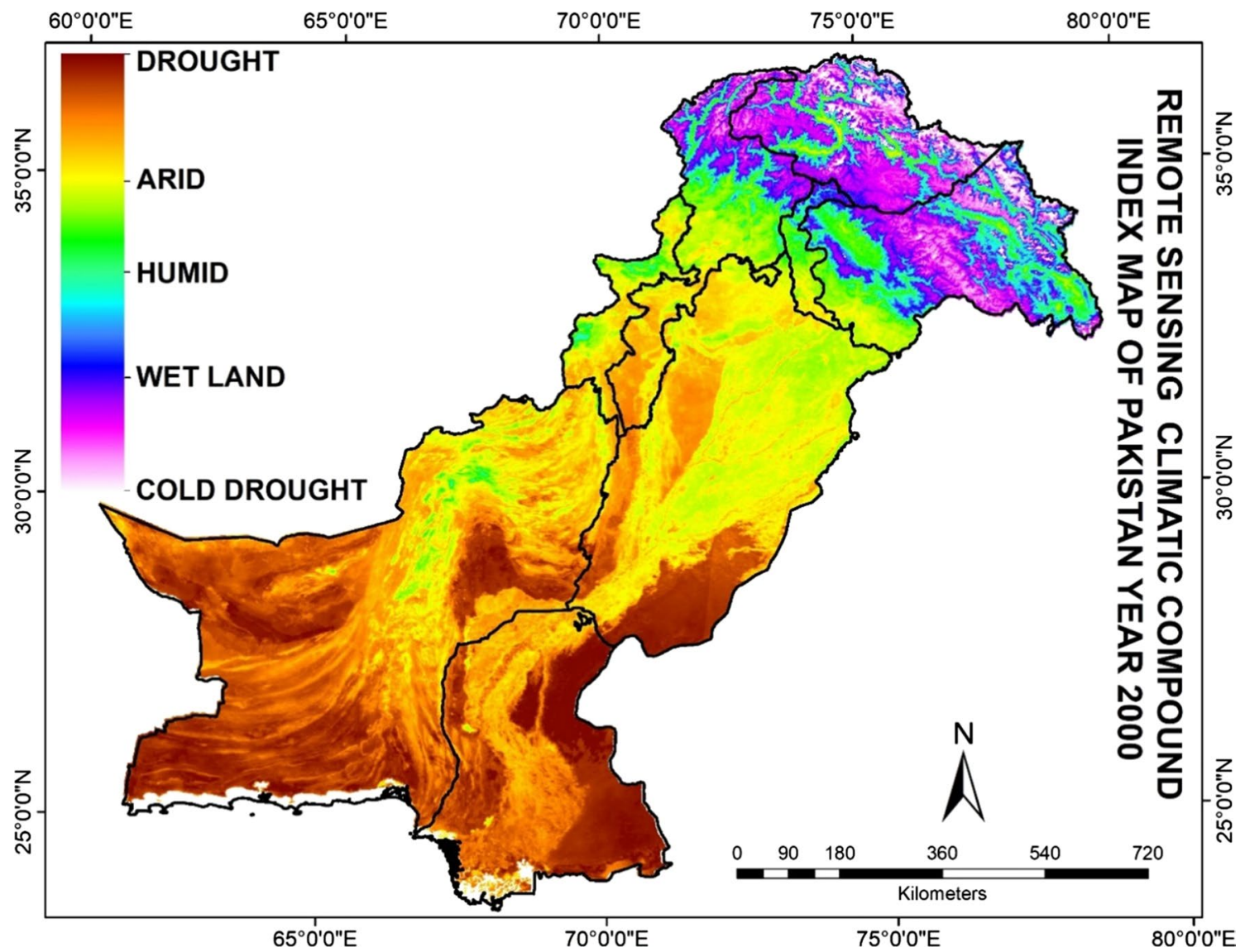

Fig. 2 The new climatic classification of Pakistan by using remotely sensed images collaborated with compound indices for year 2000 . This figure shows new climatic classification for year 2000 into further major five classes name as drought, arid, humid, wetlands and

as cold drought regions. The main change that is observed in this region causes the overall climate change in Pakistan which mainly affects this region and causes an alarming situation for the world, as well as Pakistan and its population. In these 18 years, the melting of ice and glaciers in northern Punjab not only decrease the cold drought regions but also causes unbalancing of the overall climate of Pakistan from 2000 to 2018. These maps show the new climatic classification of Pakistan at province level with remotely sensed data and also show the 18-year climatic change classification of Pakistan.

Finally, Fig. 4 and Table 2 clearly illustrate the six climatic classes of Pakistan with new techniques. A comparative graphic presentation of results of RSCCI 2000 and RSCCI 2018 is given in Fig. 4, in which the area in percentage of different classes is given. It is clearly seen in these comparative graphs that there is an increase in the arid region by $1.84 \%$ in Pakistan from $20.87 \%$ (RSCCI 2000 ) to $22.71 \%$ (RCSSI 2018), due to insufficient rainfall and negative impact of anthropogenic activities (excessive use of land due to rapid population growth, inefficient cold drought. Drought is shown with brown color scheme on the map, arid class is represented with yellow color, humid regions with green color scheme, while wetlands with blue and cyan color, and cold drought class is represented with purple color

agriculture system and deforestation for income purpose) in semiarid regions (FAO 2019; UNEP 2019). Similarly, an increase in area can be seen in wetlands and humid regions of Pakistan from RSCCI 2000 to RCSSI 2018. $1.9 \%$ increase in wetland from $8.85 \%$ (RSCCI 2000) to $10.75 \%$ (RSCCI 2018) is because of rapid melting of ice and glaciers due to global warming (WMO 2018). Consequently, there is an increase in $9.72 \%$ in area of humid region from $6.36 \%$ (RSCCI 2000) to $16.08 \%$ (RSCCI 2018). The class of drought is further subdivided into three classes to make the description more comprehensive. The subclasses are the regions of cold drought, moderate drought and intense drought classes. The area of these classes has been reduced in Pakistan from RSCCI 2000 to RCSSI 2018, which is a positive change. There is $0.78 \%$ reduction in area of cold drought region from $10.31 \%$ (RSCCI 2000) to $9.53 \%$ (RSCCI 2018). There is $8.49 \%$ reduction in area of moderate drought region from $22.97 \%$ (RSCCI 2000) to $14.48 \%$ (RSCCI 2018), while $4.19 \%$ reduction in an area of intense drought region from $30.63 \%$ (RSCCI 2000) to $26.44 \%$ (RSCCI 2018). 


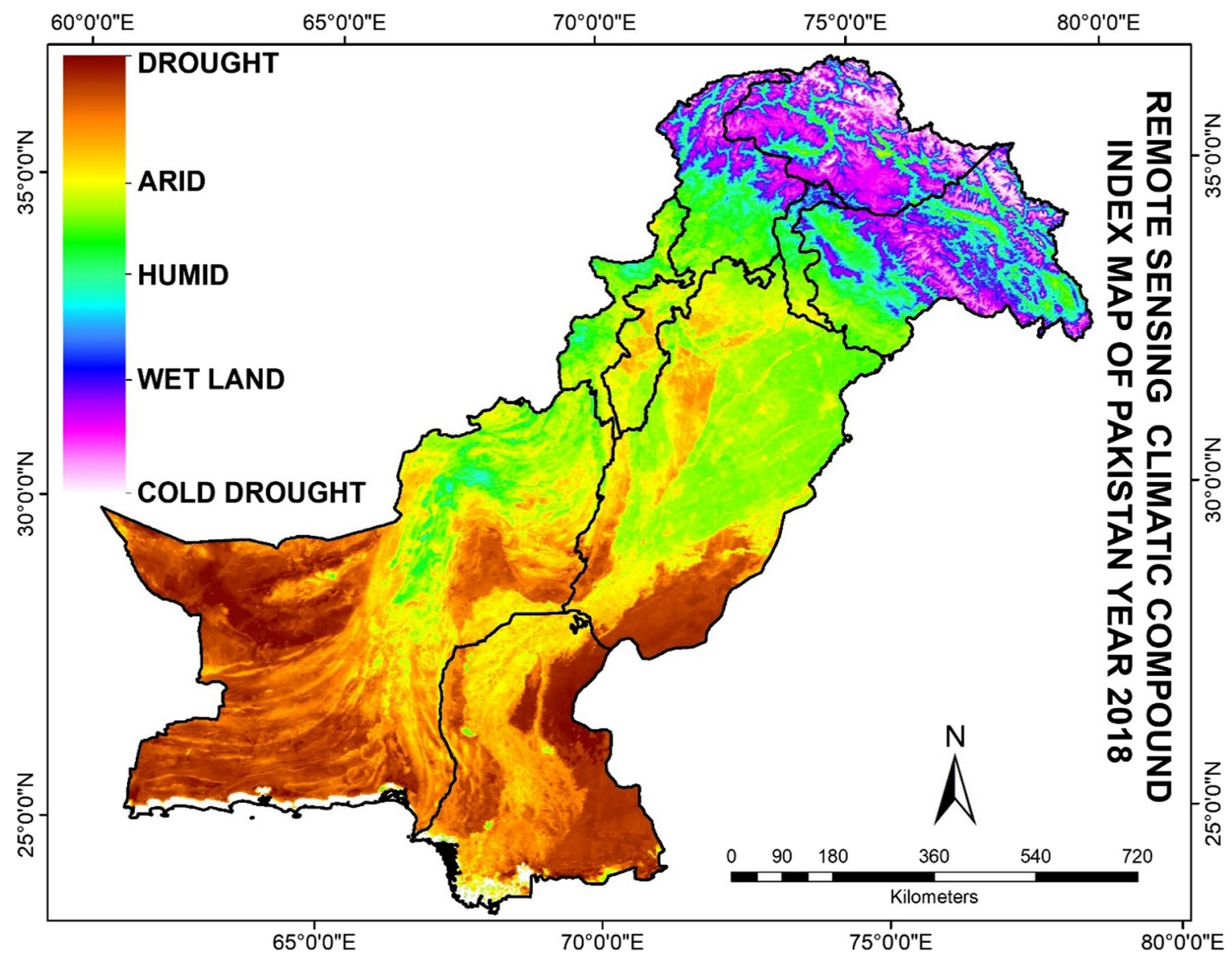

Fig. 3 The new climatic classification of Pakistan by using remotely sensed images collaborated with compound indices for year 2018 into further major five classes named as drought, arid, humid, wetlands and cold drought. Drought is shown with brown color scheme on the map, arid class with yellow color, humid regions with green color scheme, while wetlands with blue and cyan color on the map, and cold drought class is represent with purple color
Fig. 4 Comparative graphical representation of area in percentage for RSCCI 2000 and RSCCI 2018 with two color of bars. Blue color shows the area of year 2000, and orange colors shows area in percentage for all classes of year 2018

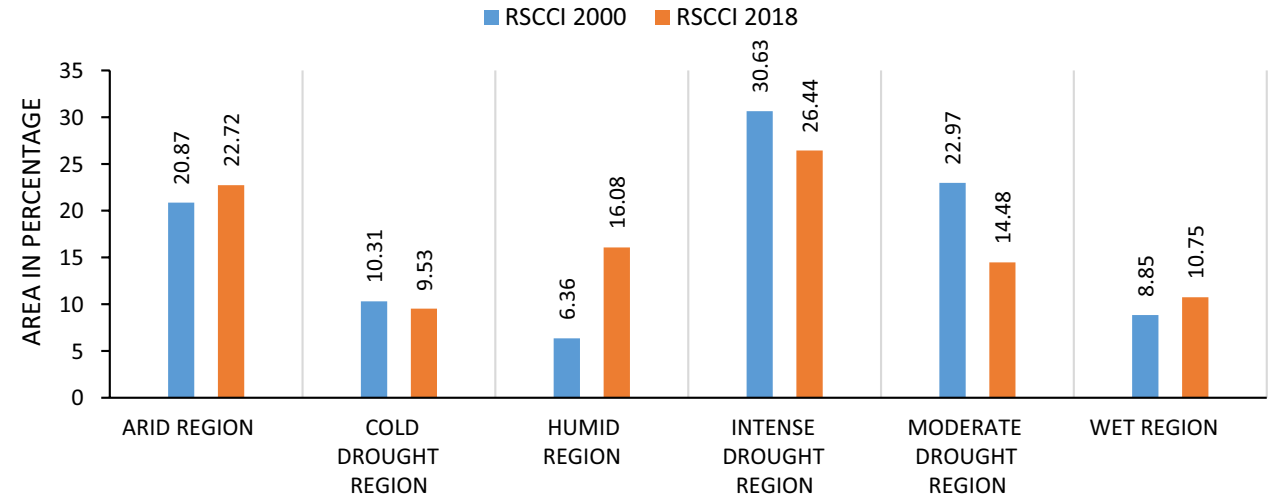

\section{Conclusions}

It is concluded from the results of this research that distinguished climatic change has been observed within the boundaries of Pakistan in a time span of eighteen years from 2000 to 2018. There is a huge change observed in these eighteen years; this dramatic climatic change is needed to be addressed on sound footing. Although the reduction in an area of drought region seems very positive for Pakistan but on the other hand increasing areas of 
Table 2 Area of climatic classification of Pakistan calculated from RSCCI for the year 2000 and 2018

\begin{tabular}{lllllr}
\hline RSCCI 2000 & & & \multicolumn{2}{l}{ RSCCI 2018 } \\
\cline { 1 - 1 } Classes & Sum Area sq.km & \% age & & Sum Area sq.km & \% age \\
\hline Arid region & 204,882 & 20.87 & & 223,534 & 22.72 \\
Cold drought region & 101,220 & 10.31 & & 93,768 & 9.53 \\
Humid region & 62,433 & 6.36 & & 158,265 & 16.08 \\
Intensely drought region & 300,652 & 30.63 & & 260,216 & 26.44 \\
Moderate drought region & 225,469 & 22.97 & & 142,454 & 14.48 \\
Wet region & 86,897 & 8.85 & & 105,763 & 10.75 \\
\hline
\end{tabular}

humidity and wetlands have created an alarming and drastic situation for the future climatic challenges of Pakistan. Pakistan is a developing country and is not ready to face abrupt climate changes. According to Germanwatch, publisher of the Climate Change Performance Index (CCPI), Pakistan is the seventh most vulnerable country in terms of climate change. As a developing country with miserable poverty and severely limited resources, the climate change has the potential to become the biggest and most destructive problem for Pakistan in the future. Therefore, precautionary measures should be designed and taken against the upcoming climatic challenges like extensive flooding, droughts, storms, heat waves and cyclones. Presented climatic classification of Pakistan can be utilized as a comprehensive mitigated tool for the said situations.

Authors' contributions Research was conducted by Ms Kanwal Javid, and manuscript was prepared and analyzed by Ms Kanwal Javid, Mrs Rumana Siddiqui and Ms Maria Mumtaz Ranjah, while Mr M Ameer Nawaz Akram reviewed the article.

Funding This research study is not funded.

Availability of data and material The datasets aquired and analysed during the current study are available in the USGS Earth Explorer website link is http://earthexplorer.usgs.gov/.

\section{Compliance with ethical standards}

Conflict of interest The authors declare that they have no conflicts of interest.

Open Access This article is distributed under the terms of the Creative Commons Attribution 4.0 International License (http://creativeco mmons.org/licenses/by/4.0/), which permits unrestricted use, distribution, and reproduction in any medium, provided you give appropriate credit to the original author(s) and the source, provide a link to the Creative Commons license, and indicate if changes were made.

\section{References}

Adam J, Sepulveda MT, Tercek RAC, Andrew MR, David PT, Blake RH, Gregory TP, Ann WR, Tom O, Juan AA (2015) The shifting climate portfolio of the greater yellowstone area. PLOS ONE 10:12

Allen R, Tasumi M, Morse A, Trezza R (2005) A landsat-based energy balance and evapotranspiration model in western US water rights regulation and planning. Irrigat Drain Syst 19(3-4):251-268

Batool R, Javid K (2018) Spatio-temporal mapping to determine LST, MSI, Ndvi and Savi over Kalat, Pakistan, pp 2024-2454

Bausch WC (1995) Remote sensing of crop coefficients for improving the irrigation scheduling of corn. Agric Water Manag 27:55-68

Benedetti R, Rossini P (1993) On the use of NDVI profiles as a tool for agricultural statistics: the case study of wheat yield estimate and forecast in Emilia Romagna. Remote Sens Environ 45(3):311-326

Blair TA (1942) Climatology, general and regional. Prentice-Hall, INC., New York, pp 484

Campell JB (1996) Introduction to remote sensing, 2nd edn. The Guilford Press, New York

Chaudhary QZ, Rasul G (2004) Agro-climatic classification of Pakistan. Sci Vis 9(1-4):59-66

Choudhury BJ, Ahmed NU, Idso SB, Reginato RJ, Daughtry CST (1994) Relations between evaporation coefficients and vegetation indices studies by model simulations. Remote Sens Environ 50(1):1-17

Friedl MA, Davis FW (1994) Sources of variation in radiometric surface temperature over a tallgrass prairie. Remote Sens Environ 48(1): 117

Gamo M, Shinoda M, Maeda T (2013) Classification of arid lands, including soil degradation and irrigated areas, based on vegetation and aridity indices. Int J Remote Sens 34(19):6701-6722

Goward SN, Tucker CJ, Dye DG (1985) North American vegetation patterns observed with the NOAA-7 advanced very high resolution radiometer. Vegetation 64(1):3-14

Greenland D (1994) Use of satellite-based sensing in land surface climatology. Prog Phys Geogr 18(1):1-15

Griffiths JF (1978) Applied climatology, 2nd edn. Oxford University Press, London, $\mathrm{p} 136$

Haroon MA, Zhang J, Yao F (2016) Drought monitoring and performance evaluation of MODIS-based drought severity index (DSI) over Pakistan. Nat Hazards 84(2):1349-1366

Huete AR (1988) A soil adjusted vegetation index (SAVI). Remote Sens Environ 25(3):295-309

Huete A, Didan K, Miura T, Rodriguez EP, Gao X, Ferreira LG (2002) Overview of the radiometric and biophysical performance of the MODIS vegetation indices. Remote Sens Environ 83(1-2):195-213

ICID Pakistan, retrieved from ICID (2005) org: http://www.icid.org/ i_d_Pakistan.pdf

Justice CO, Townshend JRG, Holben BN, Tucker CJ (1985) Analysis of the phenology of global vegetation using meteorological satellite data. Int J Remote Sens 6:1271-1318 
Kang SC, Xu YW, You QL, Flügel WA, Pepin N, Yao T (2010) Review of climate and cryospheric change in the Tibetan Plateau. Environ Res Lett 5(1):015101

Kazi SA (1951) Climatic regions of West Pakistan. Pak Geogr Rev 6(1):1-22

Khan SU, Hassan M, Khan FK, Bari A (2010) Climate classification of Pakistan. Balwois, Ohrid, pp 1-47

Koppen W (1936) Das geographisca system der klimate. In: Koppen W, Geiger GC (eds) Handbuch der klimatologie. Borntraeger, Gebr, pp 1-44

Kulkarni A, Kripalani RH, Singh SV (1992) Classification of summer monsoon rainfall patterns over India. Int J Climatol 12(3):269-280

Lyon JG, Yuan D, Lunetta RS, Elvidge CD (1998) A change detection experiment using vegetation indices. Photogramm Eng Remote Sens 64(2):143-150

Mazhar N, Shirazi SA, Javid K (2018) Desertification vulnerability and risk analysis of Southern Punjab Region, Pakistan using geospatial techniques. J Biodivers Environ Sci 12(6):273-282

Moulin SA, Bondeau A, Delecolle R (1998) Combining agricultural crop models and satellite observations: from field to regional scales. Int J Remote Sens 19(6):1021-1036

Odoh SI, Chilaka FC (2012) Climate change and conflict in Nigeria: a theoretical and empirical examination of the worsening incidence of conflict between Fulani herdsmen and farmers in Northern Nigeria. Oman Chapter Arabian J Bus Manag Rev 34(970):1-15

Peters AJ, Walter-Shea EA, Ji L, Vina A, Hayes M, Svoboda MD (2002) Drought monitoring with NDVI-based standardized vegetation index. Photogramm Eng Remote Sens 68(1):71-75

Prince SD, Kerr YH, Goutorbe JP, Lebel T, Tinga A, Bessemoulin P, Brouwer J, Dolman AJ, Engman ET, Gash JHC, Hoepffner M, Kabat P, Monteny B, Said F, Sellers P, Wallace J (1995) Geographical, biological and remote sensing aspects of the hydrologic atmospheric pilot experiment in the Sahel (HAPEX-Sahel). Remote Sens Environ 51(1):215-234

Qi J, Chehbouni A, Huete AR, Kerr YH, Sorooshian S (1994) A modified soil adjusted vegetation index. Remote Sens Environ 48(2):119-126

Rahman MDR, Islam AHMH, Rahman MDA (2004) NDVI derived sugar cane area identification and crop condition assessment, Planplus, vol 2. Urban and Rural Planning Discipline, Khula University, Bangladesh

Reddy SJ, Reddy RS (1973) A new method of estimation of water balance. In: International symposium on tropical meteorology meeting American meteorological society, Nairobi, pp 277-280

Richardson AJ, Everitt JH (1992) Using spectral vegetation indices to estimate rangeland productivity. Geocarto International 7(1):63-69

Rondeaux G, Steven M, Baret F (1996) Optimization of soil-adjusted vegetation indices. Remote Sens Environ 55(2):95-107
Rouse JW, Haas RH, Schell JA, Deering DW (1973) Monitoring vegetation systems in the Great Plains with ERTS. In: Third ERTS symposium, NASA SP-351, vol 1, pp 309-317

Sandham LA, Zietsman HL (1997) Surface temperature measurement from space: a case study in the south western cape of South Africa. S Afr J Enol Vitic 18(2):25-30

Senseman GM, Tweddale SA, Anderson AB, Bagley CF (1996) Correlation of land condition trend analysis (LCTA) rangeland cover measures to satellite-imagery-derived vegetation indices. Geocarto Int 11(3):29-38

Shamshad KM (1986) The meteorology of Pakistan: climate and weather of Pakistan. Royal Book Company, Karachi pp 313

Siddiqui S, Javid K (2018) Spatio-temporal analysis of aridity over Punjab Province, Pakistan using remote sensing techniques. Int J Econ Environ Geol 9(2):01-10

Soni C, Vaishnav DD, Bairwa D, Mittal H, Vijayvargiya H, Vijavargiya A, Singh V (2017) Automatic irrigation system. Int J Tech Res Sci

Thornthwaite CW (1931) The climates of North America: according to a new classification. Geogr Rev 21(4):633

Thornthwaite CW (1948) An approach towards rational classification of climate. Geogr Rev 38:55-64

Villmow JR (1962) Regional pattern of climates in Europe according to the Thornthwaite classification. Ohio J Sci 62(1):39-53

Walterscheid SK (2011) Climate classification for the earth's oceanic areas using the Köppen System. Diss. Kansas State University, Manhattan

White DH (1998) A global analysis of the distribution and production of the livestock communities. Report No 30 UNEP, ASIT Consulting, Hawker, pp 3-17

WMO Statement on the State of the Global Climate (2018) https://libra ry.wmo.int/doc_num.php?explnum_id=5789

Xu L, Samanta A, Costa MH, Ganguly S, Nemani RR, Myneni RB (2011) widespread decline in greenness of Amazonian vegetation due to 2010 drought. Geophys Res Lett 38:L07402

Yang Z, Willis P, Mueller R (2008) Impact of band-ratio enhanced AW IFS image to crop classification accuracy, the future of land imaging, going operational, the 17th William T. Pecora Memorial Remote Sensing Symposium, Denver

Zhang N, Hong Y, Qin Q, Zhu L (2013) Evaluation of the visible and shortwave infrared drought index in China. Int J Disaster Risk Sci

Publisher's Note Springer Nature remains neutral with regard to jurisdictional claims in published maps and institutional affiliations. 